\title{
Perinatal Findings in Pregnancy Induced Hypertension: A Study in a Tertiary Teaching Hospital in Dhaka City
}

\author{
Zobaida Sultana Susan', Surayea Bulbul², Jannat Ara Ferdows'3 ${ }^{3}$ Abu Nayeem ${ }^{4}$ \\ ${ }^{1}$ Junior Consultant (Gynaecology \& Obstetrics), Shaheed Suhrawardy Medical College Hospital, Dhaka, Bangladesh; \\ ${ }^{2}$ Junior Consultant (Gynaecology \& Obstetrics), Shaheed Suhrawardy Medical College Hospital, Dhaka, \\ Bangladesh; ${ }^{3}$ Assistant Professor (Gynaecology \& Obstetrics), Shaheed Suhrawardy Medical College \\ Hospital , Dhaka, Bangladesh; ${ }^{4}$ Assistant Professor, Department of Clinical Neurology, National \\ Institute of Neurosciences \& Hospital, Dhaka, Bangladesh
}

[Received: July 2015; Reviewed On: October 2015; Accepted on: December 2015; Published: January 2016]

\begin{abstract}
Background: Hypertensive disorders are common complication occurring during pregnancy which are responsible for maternal and fetal mortality and morbidity. Objective: The purpose of the present study was to determine the perinatal outcome in pregnancy induced hypertension. Methodology: This study was designed as cross-sectional study and was conducted from April 2013 to September 2013 for a period of six (06) moths. Patients admitted in the Department of Obstetrics and Gynaecology at Shaheed Suhrawardy Medical College Hospital, Dhaka. Data were collected by interview, physical examintions (blood pressure, pulse rate, oedema, heart and lungs auscultation) and lab investigations using a structural questionnaire. Result: Majority of the women belonged to age group 21-25 year. Maximum were (56\%) primigravida. The mean gestational age was 34.6 weeks with the range from 28 to 40 weeks. Hyperurecaemia was frequent among patients with pregnancy induced hypertension. Intrauterine growth retardation (IUGR) was secondary to pregnancy induced hypertension which was associated with significantly increased perinatal mortality. Conclusion: In this study, prematurity is frequent in pregnancy induced hypertension and convulsion in nonresponsive patients is associated with significantly increased perinatal mortality. [Journal of National Institute of Neurosciences Bangladesh, January 2016;2(1): 10-13]
\end{abstract}

Keywords: Perinatal findings; pregnancy induced hypertension; IUGR; IUD;

Correspondence: Dr Zobaida Sultana Susan, Journior Consultant (Gynaecology \& Obstetrics), Shaheed Suhrawardy Medical College Hospital, Dhaka, Bangladesh; Email: zssusan2014@gmail.com; Cell no.: +8801716067689

Conflict of interest: There is no conflict of interest to any of the authors of this article.

Funding agency: None

Contribution to authors: ZSS, SB \& JAF were contributed from protocol preparation up to report writing. AN was prepared the manuscript and was revised the manuscript.

How to cite this article: Susan ZS, Bulbul S, Ferdows JA, Nayeem A. Perinatal Findings in Pregnancy Induced Hypertension: A Study in a Tertiary Teaching Hospital in Dhaka City. J Natl Inst Neurosci Bangladesh, 2016;2(1): 10-13

Copyright: (C2016 Susan et al. Published by Journal of National Institute of Neurosciences Bangladesh. This article is published under the Creative Commons CC BY-NC License (https://creativecommons.org/licenses/by-nc/4.0/). This license permits use, distribution and reproduction in any medium, provided the original work is properly cited, and is not used for commercial purposes.

\section{Introduction}

Pregnancy induced hypertension (PIH) is the second most common medical disorder seen during pregnancy. These contribute greatly in maternal morbidity and mortality along with hemorrhage and infection ${ }^{1}$. World health organization (WHO) estimates that at least one woman dies every seven minutes from complications of hypertensive disorders of pregnancy ${ }^{2}$. Hypertensive disorders during pregnancy are associated with increased risk of adverse fetal and maternal outcomes including preterm birth, IUGR, perinatal death and antepartum haemorrhage (APH) with increased maternal mortality and morbidity ${ }^{3-5}$.

In Bangladesh maternal mortality survey (BMMS), the major causes of over half of the maternal death are due to haemorrhage $(29.0 \%)$ and eclampsia $(24.0 \%)$ and it 
has been reported that very substantial declines have occurred in both these cases, causing a $35.0 \%$ reduction in haemorrhage and 50\% reduction in eclampsia ${ }^{6}$. Severe pre-eclampsia was associated with 3 to 4 folds perinatal mortality ${ }^{7}$. Delivery is the ultimate tertiary treatment; however, management aimed at benefiting mother may be detrimental to the fetus because premature birth is a significant cause of morbidity and mortality ${ }^{8}$. Therefore the purpose of the present study was to determine the perinatal outcome in PIH.

\section{Methodology}

This was designed as cross sectional study and was conducted from April 2013 to September 2013 for a period of six (06) months. This present study was carried out in the Department of Obstetrics and Gynaecology at Shaheed Suhrawardy Medical College and Hospital, Dhaka. Patients with pregnancy induced hypertension admitted in the Department of Gynaecology \& Obstetrics were selected as study population. Women presented with gestational hypertension with or without proteinuria, ante-partum eclampsia, blood pressure more than $140 / 90 \mathrm{~mm}$ of $\mathrm{Hg}$ on at least two occasions, at least six hours apart in left lateral position if previous BP is not known, increase in single systolic BP more than $160 \mathrm{~mm} \mathrm{Hg}$ or increase in diastolic BP more than $110 \mathrm{~mm} \mathrm{Hg}$ in a single sitting were included in this study. Women presented with known case of uncontrolled diabetes mellitus, essential hypertension, heart disease, systemic lupus erythromatosus (SLE), tuberculosis, endocrine diseases, hyperlipidaemia, HTN due to systemic diseases were excluded from this study. Data were collected by interview, physical examination and lab examination using a structural questionnaire containing all the variables of interest. Statistical analysis was performed by using Statistical Package for Social Science (SPSS) version 21.0 for Windows. Quantitative variables were expressed as mean and standard deviation. Categorical variables were expressed as proportions and percentage.

\section{Results}

A total number of 50 patients with PIH were taken in this study. Majority of the study population were in the age group of 21 to 25 years which was $23(46.0 \%)$ cases followed by 16 to 20 Years and 26 to 30 Years age group which were $12(24.0 \%)$ cases and $11(22.0 \%)$ cases respectively (Table 1).
Table 1: Distribution of patients according to Age Group $(\mathrm{n}=50)$

\begin{tabular}{lcc}
\hline Age Group & Frequency & Percentage \\
\hline 16 to 20 Years & 12 & 24.0 \\
21 to 25 Years & 23 & 46.0 \\
26 to 30 Years & 11 & 22.0 \\
More than 30 Years & 4 & 8.0 \\
\hline Total & $\mathbf{5 0}$ & $\mathbf{1 0 0 . 0}$ \\
\hline
\end{tabular}

*Mean $\pm \mathrm{SD}=27.5 \pm 3.45$ (Range 19 to 37 years)

In this study $46 \%$ patients were under regular antenatal checkup. But they developed pregnancy induced hypertension. It means that it is not a preventable disease (Table 2).

Table 2: Distribution of patients by Ante-Natal Care(ANC) $(\mathrm{n}=50)$

\begin{tabular}{lcc}
\hline Ante-Natal Care & Frequency & Percentage \\
\hline Regular & 23 & 46.0 \\
Irregular & 17 & 34.0 \\
No ANC & 10 & 20.0 \\
\hline Total & $\mathbf{5 0}$ & $\mathbf{1 0 0 . 0}$ \\
\hline
\end{tabular}

Primi gravida patients were $56 \%$. It means primi gravid women have increased risk (Table 3).

Table 3: Distribution of Patients by Gravida $(n=50)$

\begin{tabular}{lcc}
\hline Gravida & Frequency & Percentage \\
\hline Primi & 28 & 56.0 \\
2 to 4 & 20 & 40.0 \\
$\geq 5$ & 2 & 4.0 \\
\hline Total & $\mathbf{5 0}$ & $\mathbf{1 0 0 . 0}$ \\
\hline
\end{tabular}

In this study $66 \%$ patients delivered premature baby which was a significant risk factor for increased the perinatal mortality (Table 4).

Table 4: Distribution of Patients by Gestational Age $(\mathrm{n}=50)$

\begin{tabular}{lcc}
\hline GA (week) & Frequency & Percentage \\
\hline 36 or $<36$ preterm & 33 & 66 \\
37 to 40 term & 17 & 34 \\
\hline Total & $\mathbf{5 0}$ & $\mathbf{1 0 0 . 0}$ \\
\hline
\end{tabular}

*Mean $\pm \mathrm{SD}=34.6( \pm 2.44) ; \mathrm{GA}=$ Gestational Age

Only $16 \%$ developed eclampsia which means + it is a preventable condition (Table 5).

Table 5: Distribution of the Patients by Diagnosis $(n=50)$

\begin{tabular}{lcc}
\hline Diagnosis & Frequency & Percentage \\
\hline Gestational hypertension & 14 & 28 \\
Pre eclampsia & 28 & 56 \\
Eclampsia & 8 & 16 \\
\hline Total & $\mathbf{5 0}$ & $\mathbf{1 0 0 . 0}$ \\
\hline
\end{tabular}


Injection $\mathrm{MgSO} 4$ was the treatment of choice in severe pre eclampsia and eclampsia which was responded in $35(70.0 \%)$ cases (Table 7$)$. In this study $76 \%$ patients responded to the treatment given which means proper management can prevent perinatal mortality (Table 8).

Table 6: Blood Pressure Level among the Study Population $(\mathrm{n}=50)$

\begin{tabular}{lcc}
\hline Blood Pressure & Frequency & Percentage \\
\hline Systolic $(\mathbf{m m ~ H g})$ & & \\
\hline 160 or $<160$ & 31 & 62 \\
$>160$ & 19 & 38 \\
\hline Diastolic $(\mathbf{m m ~ H g})$ & & \\
\hline 110 or $<110$ & 28 & 56 \\
$>110$ & 22 & 44 \\
\hline
\end{tabular}

\section{Discussion}

In addition to hypertension, there are several symptoms of pre-eclampsia which includes proteinuria and oedema. If this condition progresses to eclampsia, life threatening convulsion and coma can occur. Pregnancy induced hypertension (PIH) affects $10 \%$ of pregnancy and pre-eclampsia complicates 2 to $8 \%$ of pregnancy ${ }^{3}$. Patient with pre-eclampsia develops hemolysis, elevated liver enzymes, and low platelet count (HELLP) syndrome in 5 to $10 \%$ cases $^{4}$. Eclampsia occurs in approximately $0.2 \%$ of pregnancy and miscarriage occurs in 1 in 1000 pregnancies $^{5}$. It is more common in multiple pregnancies and in woman who had pregnancy induced hypertension (PIH) in previous pregnancy as well as other risk factors including pre-existing connective tissue disease, vascular disease and family history of pre-eclampsia and eclampsia 5 .

Table 7: Types of Different Treatments Given to Patient $(\mathrm{n}=50)$

\begin{tabular}{lcc}
\hline Types of Treatments & Frequency & Percentage \\
\hline $\begin{array}{l}\text { Rest and sedation } \\
\text { Rest and sedation and single } \\
\text { antihypertensive drug }\end{array}$ & 2 & 4.0 \\
$\begin{array}{l}\text { Rest and sedation and more than } \\
1 \text { antihypertensive drug }\end{array}$ & 5 & 16.0 \\
$\begin{array}{l}\text { Inj } \mathrm{MgSO}_{4} \text { and antihypertensive drug } \\
\text { Total }\end{array}$ & 35 & 10.0 \\
\hline
\end{tabular}

Patients presented with gestational hypertension, pre-eclampsia and ante-partum eclampsia were enrolled in this study. In this study, it was observed that majority of the women belonged to age group of 21 to 25 years. Most of the cases (62\%) came from rural areas and $24 \%$ of them were illiterate. It was also observed that maximum number of the patients were primigravida $(56 \%)$. It is also known that pre-eclampsia is a disease of nulliparous. Parmar et $\mathrm{al}^{10}$ observed that primigravida constituted $55 \%$ of total $\mathrm{PIH}$ which is comparable with the current study.

Table 8: Response to Treatment $(\mathrm{n}=50)$

\begin{tabular}{lcc}
\hline Response & Frequency & Percentage \\
\hline Positive & 38 & 76 \\
None & 10 & 20 \\
Expired & 2 & 4 \\
\hline Total & $\mathbf{5 0}$ & $\mathbf{1 0 0 . 0}$ \\
\hline
\end{tabular}

In this study, it was observed that $66 \%$ of the patients had preterm gestational age. The mean gestational age was found 34.6 week with the range of 28 to 40 week. Regular ANC was received by $46 \%$ of the patients; however, 34\% received irregular ANC and 10\% were reported without ANC. Bengal et all1 showed that majority $(80 \%)$ cases were unbooked. This disease is related to positive family history, history of hypertension and recurrence in subsequent pregnancies. Patients were treated with bed rest, sedation, anti-hypertensives and anti-convulsants. A total number of $76 \%$ patients were responded by treatment. Out of 50 patients, 2 patients were expired, 10 patients showed no response to treatment and immediate interventions were needed.

Table 9: Maternal Mortality among the Study Population $(\mathrm{n}=50)$

\begin{tabular}{lcc}
\hline Cause of Death & Frequency & Percentage \\
\hline Pulmonary oedema & 1 & 2.0 \\
PPH & 1 & 2.0 \\
\hline Total & $\mathbf{2}$ & $\mathbf{4 . 0}$ \\
\hline
\end{tabular}

Out of 50 patients, 27 patients delivered vaginally, 9 had spontaneous onset and 18 had required induction; however, $43.0 \%$ patient needed cesarean section due to uncontrolled BP, failure to progress to labour, fetal distress, previous cesarean section, CPD, mal-presentation and abruption placentae. Eclampsia is a common complication of hypertensive disorder of pregnancy. Two patients died due to pulmonary oedema and PPH which was consistent with other studies $^{12-14}$. Babies were term in $31.3 \%$ cases and preterm was in $35.4 \%$ cases, IUGR was in $20.8 \%$ cases, stillborn was $4.2 \%$ cases and intra uterine death (IUD) was in $8.3 \%$ cases. The complications due to hypertensive disease in pregnancy have steadily declined with better management, health education and good ante natal care. 


\section{Conclusion}

In this study, prematurity is frequent in pregnancy induced hypertension and convulsion. Nonresponsive patients are associated with significantly increased perinatal mortality. Maximum patients are in preterm gestational age which is a real challenge to face. Maternal mortality is the concern as the severity of the disease is subsequently reduced after delivery of the baby. Even regular antenatal checkup is not enough to overcome the disaster. It is not a preventable disease but early detection and treatment will keep hypertensive disorder under control and will reduce the incidence of severe pre eclampsia and eclampsia. Proper antenatal intervention can reduce the morbidity and mortality significantly.

\section{References}

1. Gary F. Hypertensive disorders in pregnancy. Cunningham Williams Obstetrics, 22nd edition. New York: McGraw Hill publishing division 2005,p.761

2. Dadelszen P, Magee L. What matters in pre eclampsia are the associated adverse outcomes: the view from Canada. Cur Opin Obstet Gynaecol 2008;20: 10-15

3. World Health Organization (WHO). International collaborative study of hypertensive disorders of pregnancy, Geographic variation in the incidence of hypertension in pregnancy. AMJ Obstet Gynecol 1988;80-83

4. Pre-eclampsia and Eclampsia. Themark manual. View on: 16 December 2016; [Web address: http://www.merckmanuals.com/en-ca/home/women-s-health-issues/- complications-of-pregnancy/preeclampsia-and-eclampsia] 2001; White house station, NJ

5. Niromanesh S, Lsghii S. Supplementary calcium in prevention of pre-eclampsia

6. National Institute of Population Research and Training (NIPORT) Measure evaluation, UNC-CH, USA, icddrb, Bangladesh Maternal mortality and Health Care Survey 2010-December 2012

7. Xuxiong E, Buekens P, Pridjian G, Fraser DD. The Pregnancy induced hypertension and Perinatal Mortality. J Reporod Med 2007;52:402-406

8. Magrum EF, Perry KGJ, Chauhan SP, Graves GR, Blake PG, Martin JNJ. National salvage by weeks, Gestational hypertension in pregnancy complicated by HELLP syndrome. J Soc Gynaecol Invest 1994;1:206-9

9. Reynolds SC, Mabie WC, Sibai BM. Hypertensive states of pregnancy in current Obstetrics and Gynaecology, Diagnosis and Treatment. 9th ed. DeChemey AH. Nathan (eds) McGraw Hill Company, USA 2003;p338

10. Parmer MT, Solanki HM, Gosalia VV. Study of risk factors of perineal death in pregnancy induced hypertension. Natl J Community Med 2012;3(4):703-7

11. Bengal VB, Giri PA, Mahajan AS. Maternal and fetal outcome in pregnancy induced hypertension, a study from rural tertiary care teaching hospital in India. Inter J Biomed Res 2011;2(12):595-599 12. Akhter M. Study of hypertensive disorder of hypertensive disorder of pregnancy in Mitford Hospital (BCPS Dissertation), Dhaka, Bangladesh College of Physicians and Surgeons, 1994

13. Nahar N. Maternal and Fetal Outcome of pregnancy induced hypertension in DMCH. Bangladesh College of Physician and Surgeons 2004

14. Fatema. Outcome of hypertensive disorder of pregnancy in CMH Dhaka, 2002 